\title{
Leatherback sea turtle Dermochelys coriacea visual capacities and potential reduction of bycatch by pelagic longline fisheries
}

\author{
Michael A. Crognale ${ }^{1, *}$, Scott A. Eckert ${ }^{2}$, David H. Levenson ${ }^{3}$, Craig A. Harms ${ }^{4}$ \\ ${ }^{1}$ University of Nevada, Reno, Dept. of Psychology and Program in Biomedical Engineering, Reno, Nevada 89557, USA \\ ${ }^{2}$ Wider Caribbean Sea Turtle Conservation Network (WIDECAST), Nicholas School of the Environment and Earth Sciences \\ Marine Laboratory, Duke University, Beaufort, North Carolina 28516, USA \\ ${ }^{3}$ National Marine Fisheries Service, Southwest Fisheries Science Center, La Jolla, California 92037, USA \\ ${ }^{4}$ Center for Marine Sciences and Technology, North Carolina State University, College of Veterinary Medicine, \\ Morehead City, North Carolina 28557, USA
}

\begin{abstract}
Leatherback and other marine turtles are classified as Critically Endangered or Endangered by the International Union for Conservation of Nature (IUCN), largely due to anthropogenic factors (e.g. poaching, habitat destruction and incidental mortality in fisheries). A need to understand the visual capacities of marine turtles has arisen from mortality caused by attraction of these turtles to chemiluminescent lights used by swordfish longline fisheries. Finding light sources that do not attract turtles, but enhance swordfish catch, could remove a major source of anthropogenic mortality to the Critically Endangered leatherback sea turtle. Using field-adapted non-invasive electrophysiology (corneal electroretinogram), we determined that leatherback spectral sensitivities differ significantly from those of green and loggerhead turtles with peak sensitivity in the shorter wavelengths. Leatherback temporal sensitivities also differ greatly from those of green turtles and peak at lower frequencies. Our results show that while leatherback and swordfish spectral sensitivities are similar, temporal response frequencies are very different. This difference provides a possible means to reduce the attraction of leatherbacks to swordfish longline gear by switching to electroluminescent attractants that use rapidly flickering light sources. Light sources flickered at $>16 \mathrm{~Hz}$ should be difficult for leatherbacks to detect as flickering, while remaining readily seen as flickering by swordfish.
\end{abstract}

KEY WORDS: Leatherback - Spectral and temporal sensitivity - Bycatch reduction · Fisheries · Electroretinogram $\cdot$ Photopigments $\cdot$ Flicker

Resale or republication not permitted without written consent of the publisher

\section{INTRODUCTION}

Modern marine turtles are part of an ancient lineage extending back more than 110 million years (Hirayama 1998, Gaillard et al. 2003). Only 2 families exist today, the Cheloniidae and the Dermochelyidae, and comprise a total of 7 species. The most ancient extant species, the leatherback sea turtle Dermochelys coriacea, and the only one to survive the Cretaceous-Tertiary (K-T) extinction, is also the sole living representative of the Dermochelyidae. Its lone status is exemplified by a number of unique morphological, physiological and behavioral characteristics when compared with the modern Cheloniidae. It is substantially larger and will average from 350 to $500 \mathrm{~kg}$, attaining shell lengths greater than $180 \mathrm{~cm}$ and weights in excess of $900 \mathrm{~kg}$ (Morgan 1990). Its body form is exceptionally streamlined and constructed differently from other sea turtles in that it does not have a hard, rigid carapace covered with keratinous scutes. Instead, the leatherback's carapace is formed of flexible tissue in which the ribs are embedded. This is overlain with a matrix of 1 to $2 \mathrm{~cm}$ diameter bones covered with a thin layer of skin. Its skeleton is less calcified, is quite flexible, and has a high cartilage ratio (Rhodin et al. 1981). Such divergence from other sea turtles make for a flexible, streamlined body form and, when combined with exceptionally long and broad front flippers, makes this 
species perfect for an oceanic lifestyle. With the exception of the nesting seasons and opportunistic foraging periods (Eckert et al. 2006), leatherbacks rarely enter neritic waters. The species travels almost constantly, swimming more than $10000 \mathrm{~km} \mathrm{yr}^{-1}$ (Eckert 2006, Eckert et al. 2006), and it is also a prodigious diver, exceeding $1000 \mathrm{~m}$ in dive depth with dives that may exceed 40 min (Eckert et al. 1989, 1996). Due in part to its large size (and thermal inertia), it also ranges into high latitude waters that have temperatures which approach freezing. It feeds exclusively on soft-bodied prey such as jellyfish and salps, and some of that feeding may be at night within the deep-scattering layer (Eckert et al. 1989). Such distinct morphology and oceanic lifestyle could imply unique sensory capacities when compared with other sea turtles.

The global status of the leatherback is Critically Endangered (IUCN 2004), reflecting the dramatic decline of the species over the last $20 \mathrm{yr}$. This decline has been partially attributed to the entanglement of the species in fishing gear (Eckert \& Sarti 1997), including swordfish longlines (Spotila et al. 2000, Lewison et al. 2004, Lewison \& Crowder 2007). Studies of swordfish longline fishing demonstrates that longlines equipped with light attractants such as chemiluminescent lightsticks exhibit a higher rate of capture of leatherbacks and swordfish than to do longlines without light attractants (Witzell 1999). Successful strategies for mitigating the effects of lightstick equipped longlines have been difficult to develop due to a paucity of information on the visual capacities of the leatherback.

Recent measurements of spectral sensitivity made from captive adults of 2 species of Cheloniidae, green turtles Chelonia mydas and loggerhead turtles Caretta caretta, reveal generally broad spectral sensitivity with a peak sensitivity near $580 \mathrm{~nm}$ (Levenson et al. 2004). These data, as well as those from microspectrophotometry (MSP), show the presence of multiple photopigments and spectrally selective oil droplets (Liebman \& Granda 1971). Although MSP indicates the presence of short wavelength cones, measurements made using a non-invasive electrophysiological technique, the flicker electroretinogram (ERG), reveal a reduced contribution of these cones to overall spectral sensitivity. ERG measurements also show that the overall spectral sensitivities of green and loggerhead turtles are similar, with somewhat greater sensitivity in the short wavelength region in the green turtles (Levenson et al. 2004). Finally, ERG revealed relatively reduced temporal sensitivity in these species. A similar series of measurements from leatherbacks has been lacking and, given the species' distinct morphology, physiology and preferred oceanic lifestyle, might be expected to be different.

\section{MATERIALS AND METHODS}

Apparatus. Due to the inability to hold leatherbacks in captivity, application of the ERG technique to adult leatherbacks required us to conduct the experiments under field conditions. We, therefore, developed a portable, self-contained ERG lab that could be used on a nesting beach where access to turtles was assured. The general ERG methods used in the present leatherback experiments were similar to those described in detail previously (Levenson et al. 2004). Briefly, stimuli for eliciting the ERG were presented via a 3-channel optical system (Maxwellian view) wherein the source is imaged in the plane of the pupil and the image formed on the retina is that of the final lens. This system allows for large stimulus fields and high light intensities. The test and reference channels shared a tungsten/halogen source while the third adaptation channel utilized a separate tungsten/halogen source. The test channel was spectrally filtered using a tunable interference filter (CRI). The intensity of this channel was controlled with a circular neutral density wedge. The spectral content and intensity in the other 2 channels was controlled with interference filters and neutral density step filters. Presentation of light from each channel was controlled via electromechanical shutters (Uniblitz). Each channel utilized cold mirrors and/or heat absorbing glass to reduce retinal exposure to heat.

Adult leatherback ERGs were recorded with BurianAllen contact lens-style corneal electrodes (Hanson) from 7 adults (275 to $445 \mathrm{~kg}$ ). Small stainless steel loops were positioned on the cornea for recording from hatchlings. Adult ERGs were referenced to the electrode speculum while those of hatchlings were referenced to the head with a small subcutaneous needle. The turtles were electrically grounded via subcutaneous needle electrodes positioned on a flipper. ERG signals were differentially amplified (Grass, CP511), filtered, then digitized, analyzed, and stored in a laptop computer via an I/O card (National Instruments, DAQCard 6024E). For adult recording on the beach, the equipment was powered by high capacity deep discharge $12 \mathrm{~V}$ batteries and a 12 to $110 \mathrm{~V}$ sine-wave inverter. The hatchlings recordings were made at a nearby field station with line current available. As a control for differences in power sources, several hatchlings were tested in the field station using the battery and inverter while line current at the field station was utilized for other hatchling experiments. There was no detectable difference in signal quality between these 2 conditions. Hatchlings were placed in a modified small-animal stereotaxic apparatus wherein the ear bars were replaced with padded holders to cradle the sides of the hatchling shell and front flippers. 
Anesthesia. Because of the small signal and myogenic contribution to noise in the ERG, we first developed an anesthesia protocol and dosage response models for the species (Harms et al. 2007). After egg deposition and weighing, adult females were anesthetized using $8 \mathrm{mg} \mathrm{kg}^{-1}$ ketamine and $80 \mu \mathrm{g} \mathrm{kg}$ medetomidine intravascularly. These anesthetics have been shown to provide a protective effect on the retina and do not suppress activity (Tsukahara et al. 1992, Dong et al. 2007). Response times, respiratory rate, heart rate, electrocardiogram, and cloacal temperature were monitored, and blood was collected for hematology, plasma biochemistries, and blood gases. At the end of the ERG procedure, atipamezole was administered at 150 to $420 \mu \mathrm{g} \mathrm{kg}^{-1}$ (5× the dose of medetomidine), half intramuscularly and half intravascularly. The turtles were monitored and prevented from reentering the water until normal behavior had returned. The observed within-season return nesting rate of anesthetized turtles was comparable to that for turtles not anesthetized (Harms et al. 2007). In hatchlings, the doses were 4 to $6 \mathrm{mg} \mathrm{kg}^{-1}$ ketamine and 40 to $60 \mu \mathrm{g}$ $\mathrm{kg}^{-1}$ medetomidine intravascularly (all but one were dosed at 5 to $6 \mathrm{mg} \mathrm{kg}^{-1}$ ketamine and 50 to $60 \mu \mathrm{g} \mathrm{kg}$ medetomidine) and reversed with atipamezole 200 to $300 \mu \mathrm{g} \mathrm{kg}^{-1}$ (half intravascularly and half intramuscularly). Due to their small size, hatchling anesthetic monitoring was more limited than with the adults, but all reached a suitable plane of anesthesia for the ERGs and recovered well.

Procedure. Adult female leatherbacks were located by monitoring a protected nesting beach (Matura) in Trinidad. A large padded sling was placed under female turtles during egg-laying. When the nesting females had completed egg-laying and begun the nest-covering phase, they were weighed by hoisting them with a pulley system attached to a digital scale suspended from a large aluminum tripod (after Eckert et al. 1989). The turtles were then anesthetized, and the nests were covered by hand. To protect the equipment from the rain and wind-driven sand, a tent was set up and positioned so that the turtle's head was inside one of the doors of the tent. To avoid large head movements due to opening of the lower jaw during respiration, the head was suspended slightly off the ground using a cord attached to a small tripod and slung under the turtle's upper jaw, allowing free opening of the lower jaw without head movement. Emergent hatchling turtles were collected on the same beach and brought back to the field station for testing. Mydriatics (phenylephrine) and corneal anesthetics (proparacaine hcl) were administered topically prior to placement of the corneal electrodes, although there was no evidence that the mydriatics had an effect on pupil size. To test for diurnal variations, 4 of the hatch- ling turtles were tested at night, 8 were tested during the day. We also were able to test 1 of the 5 adult turtles during the day.

In one experimental procedure we utilized a flicker photometric ERG procedure (FPERG), a technique that produces rapid and reproducible spectral sensitivities (Jacobs et al. 1996). In this procedure the stimuli are flashes of monochromatic test lights of variable chromaticity and intensity, interleaved with flashes of an achromatic reference light of fixed intensity. We employed flicker frequencies between 4 and $12 \mathrm{~Hz}$ for the spectral sensitivity determinations. Response amplitudes were determined using Fourier analysis by calculating the magnitude of the component in the response that corresponded to the flicker frequency (fundamental). The responses from different intensities of the test flashes were electronically compared with those from the fixed reference lights. An intensity of the test light that produced responses of equivalent magnitude to the responses elicited by the reference light was found. The test intensity at this equation point, i.e. that intensity where both the test response and the reference response amplitudes are equal, is taken as a measure of response threshold. A family of equations measured at different test wavelengths is used to define the relative spectral sensitivity function. In a second procedure (the intensity response or IR procedure) spectral sensitivities are calculated from fixed criterion amplitudes chosen as thresholds from intensity-response functions (Fig. 1). A family of such thresholds measured for different wavelengths of flickering test lights produces spectral sensitivities. Spec-

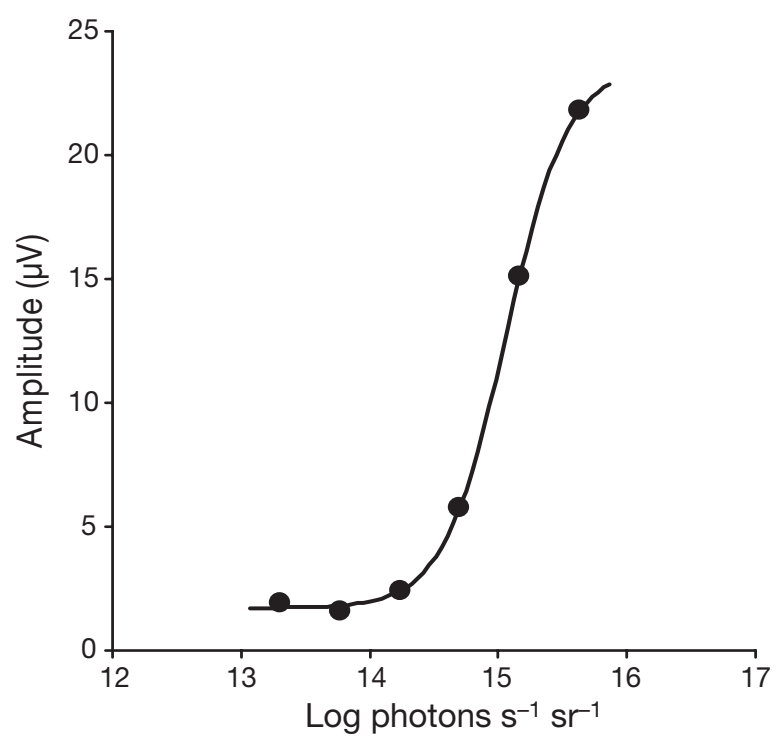

Fig. 1. Example of electroretinogram (ERG) response to increasing light. Amplitude of the retinal response to flickering (12 Hz) $580 \mathrm{~nm}$ test lights shown. Solid curve is the best fitting Michaelis-Menten function 
tral sensitivities measured in this manner are more difficult to obtain and contain more noise from fluctuations in overall retinal responses, but the measurements can be extended further into the spectral extremes than those from the FPERG procedure, which tends to be more limited by available light. Temporal sensitivity functions were also determined using the IR procedure except that flicker rate was varied over a range from 4 to $40 \mathrm{~Hz}$ in $4 \mathrm{~Hz}$ increments using $580 \mathrm{~nm}$ test lights.

\section{RESULTS}

The ERG technique allows for rapid and objective assessment of both spectral and temporal sensitivity. Reliable ERGs were obtained from 5 of the adult leatherbacks and 12 of the hatchlings. Fig. 1 shows an example of the change in amplitude of the fundamental frequency in the ERG signal as a function of intensity of a $580 \mathrm{~nm}$ test light in one adult leatherback turtle. The solid curve is a best-fitting MichaelisMenten equation:

$$
R=\frac{I^{\eta}}{I^{\eta}+k} V_{\max }
$$

wherein $R=$ response, $I=$ intensity of light, $\eta=1.81, k=$ $15.1 \log$ photons $\mathrm{s}^{-1} \mathrm{sr}^{-1}$, and $V_{\max }=21.9 \mu \mathrm{V}$. The parameter fits $\left(\eta, k\right.$, and $\left.V_{\max }\right)$ are in reasonable agreement with those reported for green and loggerhead turtles previously (Levenson et al. 2004).

Fig. 2 shows spectral sensitivities constructed from a family of intensity response functions as in Fig. 1 utilizing a criterion response of $4 \mu \mathrm{V}$. The data sets have been positioned vertically to ease comparison. The adult $(\mathrm{n}=2)$ and hatchling $(n=6)$ spectral sensitivities appear to be based upon similar photopigment complements although the relative weighting of these to the retinal response may differ somewhat as evidenced by the relative differences between the long and short wavelength sensitivities. It is also clear from comparison to the $500 \mathrm{~nm}$ pigment spectral sensitivity curve (Lamb 1995) that there are at least 2 photopigments contributing to the shape of the spectral sensitivity functions in both adult and hatchling leatherbacks. Comparison with the spectral sensitivities previously reported for green turtles (data from Levenson et al. 2004) reveals a likely common long wavelength photopigment, peaking at about $580 \mathrm{~nm}$, with a sensitivity differing from that of a typical rod, which would have a peak near $500 \mathrm{~nm}$. However, relative short wavelength sensitivity in leatherbacks far exceeds that of green turtles.

Fig. 3 shows spectral sensitivities obtained using the FPERG method in adult leatherbacks using 2 different flicker rates: $8 \mathrm{~Hz}(\mathrm{n}=3)$ and $12 \mathrm{~Hz}(\mathrm{n}=2)$. Spectral sensitivities were not measurable above $12 \mathrm{~Hz}$. Fig. 3 also shows the spectral sensitivity for a $500 \mathrm{~nm}$ pigment (solid line) and that of the green turtle (dashed line) from Levenson et al. (2004). The curve obtained at $8 \mathrm{~Hz}$ shows clear contribution from a long wavelength

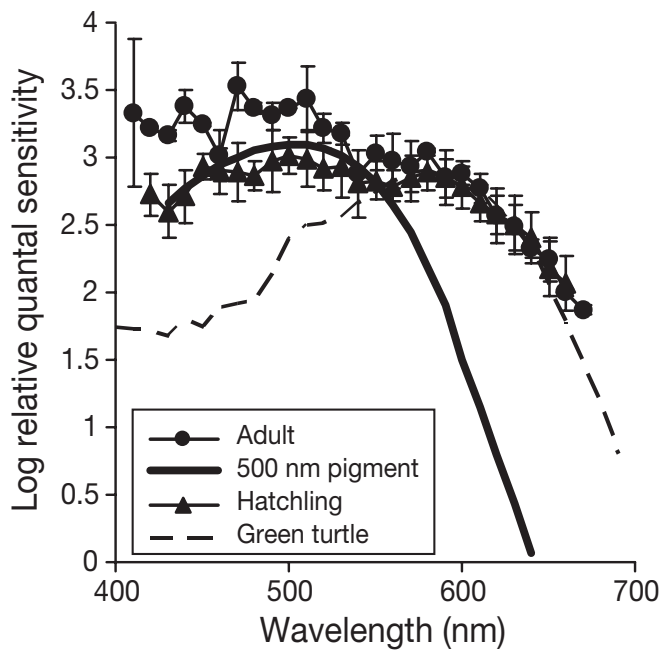

Fig. 2. Adult and hatching leatherback Dermochelys coriacea. Sensitivity changes with wavelength as measured by the electroretinogram (ERG). Log relative quantal sensitivity functions for adult and hatchling leatherback sea turtles shown. Also shown for comparison are the data from green sea turtles (Levenson et al. 2004) and a rod photopigment $\left(\lambda_{\max }=500 \mathrm{~nm}\right.$, from Lamb 1995) curve. Error bars indicate \pm 1 SEM. Where there are no error bars, SEMs were smaller than the data points

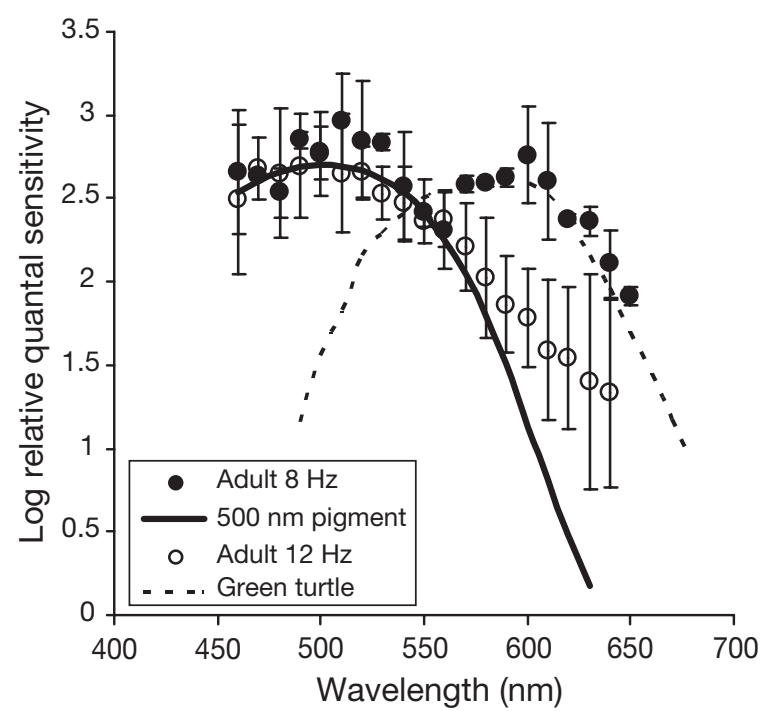

Fig. 3. Dermochelys coriacea. Adult leatherback sensitivity changes with wavelength as measured by the flicker photometric electroretinogram (ERG). Log relative quantal sensitivity functions collected at 8 and $12 \mathrm{~Hz}$ shown. Absorption curve for a rod photopigment $\left(\lambda_{\max }=500 \mathrm{~nm}\right.$, from Lamb 1995) is also shown for comparison as is the spectral sensitivity of the green turtle. Error bars indicate \pm 1 SEM 
pigment that appears similar to that seen in the green turtle. The curve also shows high sensitivity in the shorter wavelength region of the spectrum, indicating the presence of additional pigments near $500 \mathrm{~nm}$. When tested at $12 \mathrm{~Hz}$, the spectral sensitivity departs significantly from the $500 \mathrm{~nm}$ curve in the long wavelengths but to a much lesser degree than does the sensitivity obtained at $8 \mathrm{~Hz}$. Since individual photopigment spectra do not change shape with flicker frequency (univariance), the change in shape of the spectral sensitivity function shown here indicates that there must be more than one photopigment contributing to the shape of the spectral sensitivity functions. In addition, the data indicate that the longer wavelength pigment may have poorer temporal resolution than the shorter wavelength pigment(s).

Fig. 4 shows spectral sensitivities obtained using FPERG in 3 adult and 4 hatchling turtles. The adults were tested at $8 \mathrm{~Hz}$, while the hatchlings were tested at 12 and $16 \mathrm{~Hz}$. As described below, the use of slower recording conditions was necessary for the adults in order to reveal the presence of the long wavelength pigment. The data confirm the previous measurements from Fig. 2 and show clear evidence of at least 2 photopigments in the leatherbacks that cannot be accounted for with a single rod-like $(500 \mathrm{~nm})$ photopigment. Under these conditions, the adults and hatchlings show similar spectral sensitivities. The longer wavelength pigment appears to be similar to that observed in green (dashed line, Fig. 2) and loggerhead turtles (Levenson et al. 2004).

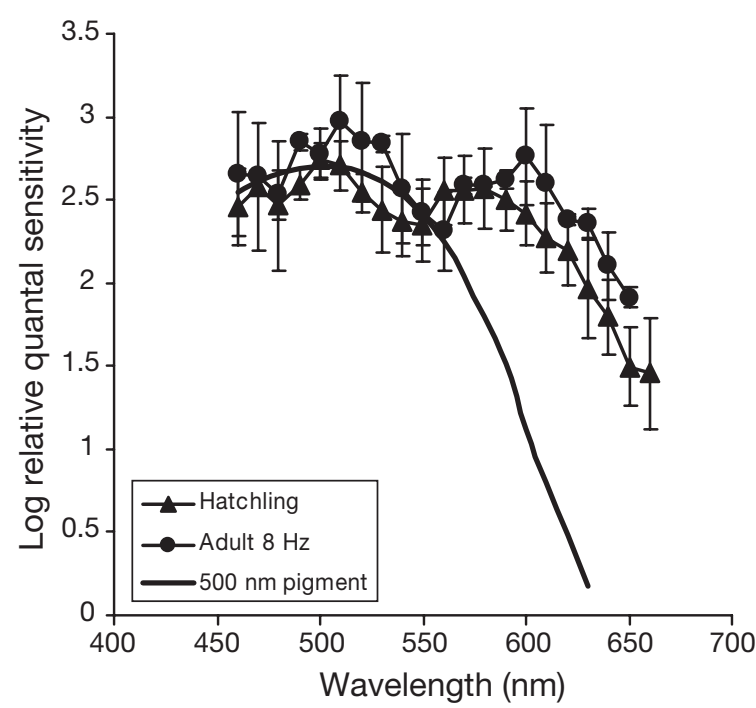

Fig. 4. Dermochelys coriacea. Adult and hatchling leatherback sensitivity changes with wavelength as measured by the flicker photometric electroretinogram (ERG). Log relative quantal sensitivity functions shown. Absorption curve for a rod photopigment $\left(\lambda_{\max }=500 \mathrm{~nm}\right.$, from Lamb 1995) is also shown for comparison. Error bars indicate \pm 1 SEM
Because the relative populations of the different cone classes can be highly skewed, revealing the presence of less numerous photopigments often requires additional measures. Fig. 5 shows the results from an experiment designed to reveal the presence of additional photopigments in the short wavelength region of the spectrum. This experiment tests for univariance of the shape of the spectral sensitivity function. The principle of univariance states that shape of the spectral sensitivity for a single photopigment does not change in the presence of spectrally biased adapting lights. However, if there is more than 1 photopigment contributing to the shape of the spectral sensitivity function, then a shift in the shape of the function is expected with chromatic adaptation as 1 pigment's sensitivity will be relatively more suppressed by the adaptation. This change in shape of the function due to adaptation would be reflected as a shift in the difference in sensitivity between 410 and $430 \mathrm{~nm}$ plotted in Fig. 5. In contrast, univariance in the shape of the spectral sensitivity function in the presence of chromatic adaptation argues against the presence of additional photopigments. The data in Fig. 5 reveal a failure in univariance for 2 hatchling turtles tested at 410 and $430 \mathrm{~nm}$, with and without strong chromatic adaptation $(450 \mathrm{~nm})$. The hatchlings showed a loss in sensitivity to $430 \mathrm{~nm}$ relative to that at $410 \mathrm{~nm}$ with adaptation (1-tailed $t$-test, $\mathrm{p}<0.006)$. If there were only a single pigment present, then there should be no difference between the adapted and unadapted conditons. However, the data show that sensitivity to a $430 \mathrm{~nm}$ light is

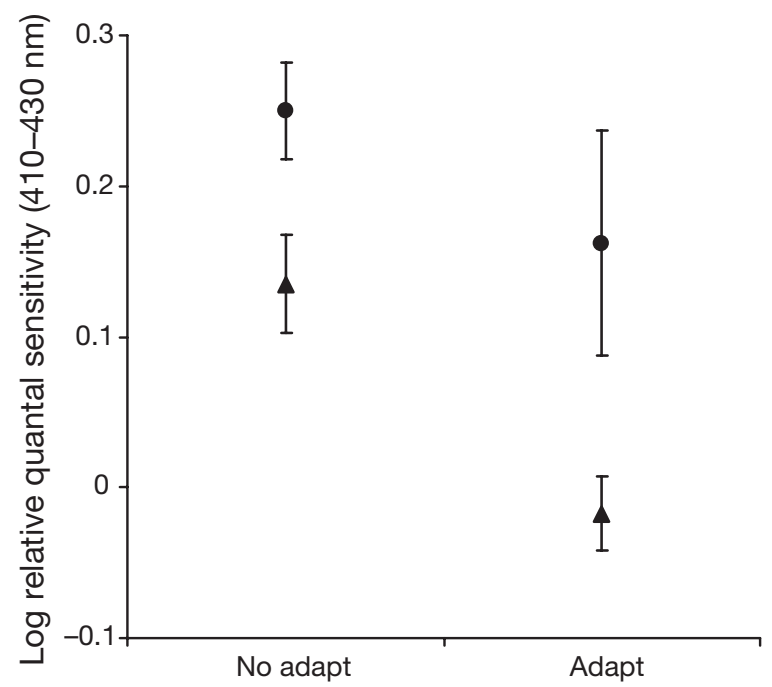

Fig. 5. Dermochelys coriacea. Shift in leatherback spectral sensitivity caused by adaptation. Chromatic adaptation was used as a test of univariance and the presence of multiple photopigments. Relative spectral sensitivity between 410 and $430 \mathrm{~nm}$ test lights in the presence and absence of a $450 \mathrm{~nm}$ adaptation light. Results shown for 2 hatchling turtles $(\mathrm{H} 15:-$, and H16: $\boldsymbol{\Delta})$. Error bars indicate \pm 1 SEM 
depressed more than that for a $410 \mathrm{~nm}$ test light in the presence of a $450 \mathrm{~nm}$ adapting light. This change of shape (failure of univariance) of the spectral sensitivity in the presence of adaptation is small but in the expected direction for the presence of at least 2 photopigments contributing to spectral sensitivity in this part of the spectrum and for one of these pigments to have peak sensitivity shorter than the $450 \mathrm{~nm}$ adapting light.

Temporal sensitivity functions obtained with the ERG are presented in Fig. 6. The adult $(\mathrm{n}=6)$ and hatchling $(\mathrm{n}=8)$ data are shown as well as the data from adult green turtles $(n=3)$ (unpubl. data from Levenson et al. 2004 study). The leatherback data are strikingly low-pass in nature, being most sensitive at the lowest measured frequencies, and differ from the band-pass data of the green turtles, which has a distinct maximum near $10 \mathrm{~Hz}$. The greater relative sensitivity at the high frequencies for the hatchling turtles versus the adults is also striking and may be due to relatively higher retinal illumination inherent to smaller eyes. Although the Maxwellian optical system largely discounts the smaller pupil size of the hatchlings, eye size would continue to be a factor under natural illumination since the pupil to retinal area decreases with age (auuthors' unpubl. obs.). It is not known whether or not green turtle hatchlings also show superior temporal response to adult green turtles. The low-pass (peaking in the low frequency end) tuning in the leatherback demonstrates poor temporal

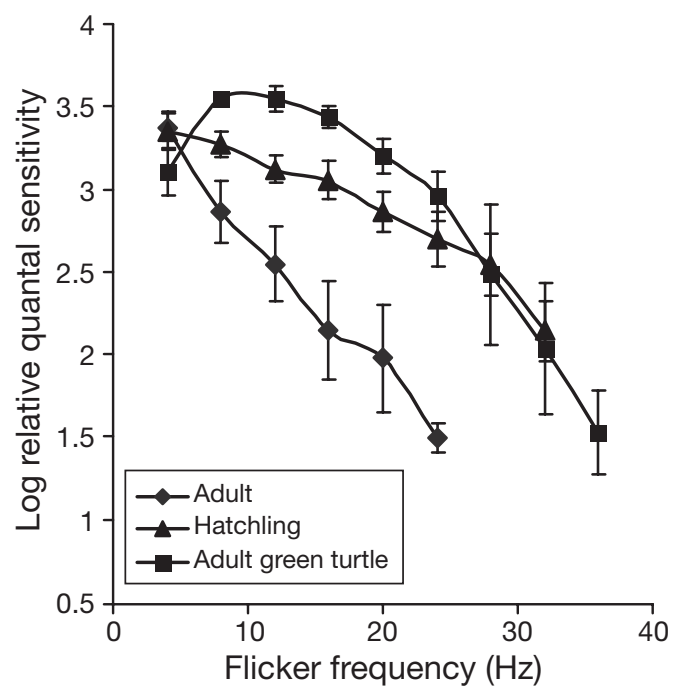

Fig. 6. Dermochelys coriacea. Changes in sensitivity with increasing flicker rate. Temporal sensitivity functions for adult and hatchling leatherback turtles shown. Flickering $580 \mathrm{~nm}$ test lights were presented in a square-wave mode with a $25 \%$ duty cycle (on $25 \%$, off $75 \%$ ). Also shown are data collected in 2004 from green turtles (D. H. Levenson, S. A. Eckert, M. A. Crognale, J. F. Deegan, O. H. Jacobs unpubl. data). Error bars indicate \pm 1 SEM resolution, particularly in the adult. The data, however, also suggest that temporal inhibition provided by lateral neural connections in the retina mechanisms that are believed to produce band-pass (peaking in the middle) tuning functions in many other species (Watson 1986) may not be present in the leatherback. The temporal response properties observed here suggest sluggish photoreceptors such as rods. However, the spectral sensitivities clearly argue for the activity of a photoreceptor with a long wavelength peak not often observed in rods but common in cones. The existence of rod-like cones or cones with rod-like spectra in the leatherback has not previously been reported.

To test for circadian shifts in sensitivity 8 of 12 hatchlings and 1 of 5 adults were tested during the day while the remainder were tested at night. Comparison of data collected during the day and data collected at night for both hatchlings and adults failed to reveal any evidence of circadian shifts for either spectral or temporal sensitivities.

\section{DISCUSSION}

The present results support the conclusion that the visual capacities of leatherback turtles are different from those of green and loggerhead turtles though they apparently possess photopigments in common. Leatherback spectral sensitivity strongly favors short wavelengths as might be expected from a deep diving, oceanic animal, where low light capability is favored over broad spectral sensitivity. These differences might well have given rise to differences in retinal photoreceptor complements and associated spectral sensitivity as is seen in a wide variety of both terrestrial and marine species (e.g. Jacobs 1993, Bowmaker 1995, Jacobs et al. 1996, Levenson et al. 2004).

A recent review by Southwood et al. (2008, this Theme Section) cites some of our preliminary findings that revealed differences between the spectral sensitivities of leatherbacks and those of green and loggerhead turtles. These preliminary data were collected at night whereas our previous green and loggerhead data were collected during the day, raising the possibility of circadian fluctuations rather than species differences as a cause of the discrepant spectral sensitivities. The present data set included both day and night testing, wherein there were no observable shifts in spectral or temporal sensitivity. These observations render circadian fluctuations an unlikely explanation for the spectral sensitivity differences.

Can the information gathered in these experiments assist us in reducing the attractiveness of longline fishing gear to leatherback sea turtles? As noted, swordfish longlines equipped with chemiluminescent 
attractors and fished at night entangle more leatherback turtles (Witzell 1999). Such light attractorequipped longlines also catch more swordfish (Hazin et al. 2005, Damalas et al. 2006), and so discontinuing their use would not be desired by fishers. However, reducing the attractiveness of such devices to leatherbacks, while maintaining their attractiveness to swordfish, could resolve some of the entanglement problems.

Our data suggest that spectral changes in lightsticks to longer wavelengths, would make them relatively less detectable by leatherbacks since these turtles are most sensitive to shorter wavelengths. However, spectral detection capabilities in swordfish are similar to leatherbacks (Fritschens \& Warrent 2004, Fritsches et al. 2000, 2005), so it is likely that longer wavelengths would also be less attractive to swordfish. Flickering the light source, however, may be more beneficial to the conservation of leatherbacks. Our data show that adult leatherbacks have a greatly reduced ability to detect lights flickering at greater than $16 \mathrm{~Hz}$. While leatherbacks have relatively slow temporal responses, swordfish have a rapid temporal response, particularly at shallower (and warmer) depths (Fritsches et al. 2005), where they forage at night (Carey \& Robison 1981). Further it has been shown that swordfish enhance flicker sensitivity by warming the eye using a specialized heating system located within extraocular muscles. It is proposed that this is a feature to allow for greater eye performance in hunting fastmoving prey (Fritsches et al. 2005). Such an eyeheating capacity has not been identified in leatherbacks, and it is likely that such a capacity does not exist, as they do not hunt fast-moving prey.

Low flicker sensitivity results in lower visibility for at least 2 reasons: (1) Simple linear temporal integration of light by a detector means that a flashing light that was perceived as steady and was illuminated only $25 \%$ of the time ( $25 \%$ duty cycle) would be $75 \%$ dimmer than a steady light of the same radiant output. (2) Visual systems so far examined have specialized pathways to detect motion and flicker (e.g. Lee et al. 1989, Crognale \& Jacobs 1991). The neurons in these pathways respond transiently, are very sensitive to low contrast changes, and contribute enormously to detection. The large contribution to behavior from these neurons are the reason why flickering and moving stimuli are easiest to detect and also the reason why even suprathreshold stimuli such as flashing warning lights are most salient to vision. In visual systems, the neurons with the lowest temporal resolution will limit the resolution of the system. Thus, if the retinal neurons have limited resolution, then the system itself cannot exceed these limits. In species so far examined, the retinal neurons, in fact, have higher temporal resolu- tion than the rest of the system, which is apparently limited at the level of the cortex (e.g. Lee et al. 1989, Crognale \& Jacobs 1991). It is, therefore, possible that the temporal response of the leatherback is even worse than that measured at the retina. Such limited temporal response in the leatherback visual pathways would certainly limit the capacity of these transient pathways to improve detection. It is also of interest that the long wavelength sensitivity in the leatherback is particularly reduced at moderately high flicker rates of about $12 \mathrm{~Hz}$.

The reason for such a distinct difference in temporal performance between leatherbacks and swordfish probably can be attributed to the respective diets. As highly efficient visual predators of other fish, it is advantageous for the swordfish to have visual neural responses that enable high resolution and detection of rapidly moving prey. In contrast, leatherbacks feed on jellyfish, which do not move quickly and may even luminesce. To the leatherback good low light vision and high spectral resolution in short wavelengths is more important than high temporal performance.

While controlled flickering is probably not feasible with chemiluminescent fish attractors, the recent development of electroluminescent devices which use light-emitting diodes (LEDs) for a light source (www.lindgren-pitman.com/c-4-eletralume.aspx) is a promising solution. LEDs can be used to provide very specific spectral properties and can also be flickered at controlled rates.

\section{CONCLUSIONS}

Leatherback sea turtles are low-light, short-wavelength vision specialists. They are less sensitive in the long wavelengths than the short wavelengths and possess a sluggish visual system. Such visual performance is distinct among sea turtle species (at least among those whose visual capacities are known), which have excellent long wavelength sensitivity and more rapidly reacting photopigments. Such a contrast might be expected given the deep diving, oceanic existence of the leatherback when compared with the neritic lifestyle of other marine turtles. By understanding the visual capabilities of the leatherback, we are able to propose a potential solution to a difficult conservation problem for this Critically Endangered species. Swordfish fisheries which commonly use chemior electro-luminescent light sources to attract swordfish also attract and kill leatherback sea turtles. If those sources were designed to flicker at $>16 \mathrm{~Hz}$, the slow responding eye of the leatherback would have greater difficulty detecting its presence than would pelagic fish. 
Acknowledgements. We thank P. Duhamel, A. E. Eckert, S. Haber, J. Highsmith, S. Kubis, K. McDermott, A. Tuttle, and Nature Seekers, Trinidad. This work was supported by the US Dept. of Commerce, National Marine Fisheries Service and the Wider Caribbean Sea Turtle Conservation Network (WIDECAST).

\section{LITERATURE CITED}

Bowmaker J (1995) The visual pigments of fish. Prog Retin Eye Res 15:1-31

Carey FG, Robison BH (1981) Daily patterns in the activities of swordfish, Xiphias gladius, observed by ultrasonic telemetry. Fish Bull (Wash DC) 79:277-292

> Crognale MA, Jacobs GH (1991) Behavioral and electrophysiological sensitivity to temporally modulated stimuli in the ground squirrel. Vis Neurosci 6:593-606

Damalas D, Megalofonou P, Apostolopoulou M (2006) Environmental, spatial, temporal and operational effects on swordfish (Xiphias gladius) catch rates of eastern Mediterranean Sea longline fisheries. Fish Res 84:233-246

Dong C-J, Guo Y, Wheeler L, Hare WA (2007) $\alpha 2$ adrenergic receptor-mediated modulation of cytosolic $\mathrm{Ca}^{++}$signals at the inner plexiform layer of the rat retina. Invest Ophthalmol Vis Sci 48:1410-1415

Eckert SA (2006) High-use areas for Atlantic leatherback sea turtles (Dermochelys coriacea) as identified using satellite telemetered location and dive information. Mar Biol 149: $1257-1267$

Eckert SA, Sarti LM (1997) Distant fisheries implicated in the loss of the world's largest leatherback nesting population. Mar Turtle Newsl 78:2-7

Eckert SA, Eckert KL, Ponganis P, Kooyman GL (1989) Diving and foraging behavior of leatherback sea turtles (Dermochelys coriacea). Can J Zool 67:2834-2840

Eckert SA, Liew HC, Eckert KL, Chan EH (1996) Shallow water diving by leatherback turtles in the South China Sea. Chelonian Conserv Biol 2:237-243

Eckert SA, Bagley D, Kubis S, Ehrhart L, Johnson C, Stewart K, DeFreese D (2006) Internesting, post-nesting movements and foraging habitats of leatherback sea turtles (Dermochelys coriacea) nesting in Florida. Chelonian Conserv Biol 5:239-248

Fritsches K, Warrant E (2004) Do tuna and billfish sea colours? Pelagic Fish Res Prog 9:1-4

Fritsches KA, Partridge JC, Pettigrew JD, Marshall J (2000) Colour vision in billfish. Phil Trans R Soc Lond Ser B Biol Sci 355:1253-1256

Fritsches KA, Brill RW, Warrant EJ (2005) Warm eyes provide superior vision in swordfishes. Curr Biol 15:55-58

Gaillard C, Bernier P, Barale G, Bourseau JP and others (2003) A giant Upper Jurassic turtle revealed by its trackways. Lethaia 36:315-322

Harms CA, Eckert SA, Kubis SA, Campbell M, Levenson DH, Crognale MA (2007) Field anaesthesia of leatherback sea turtles (Dermochelys coriacea). Vet Rec 161:15-21

Editorial responsibility: Brendan Godley, University of Exeter, Cornwall Campus, UK
Hazin HG, Hazin FHV, Travassos P, Erzini K (2005) Effect of light-sticks and extralume attractors on surface-longline catches of swordfish (Xiphias gladius, Linnaeus, 1959) in the southwest equatorial Atlantic. Fish Res 72:271-277

> Hirayama R (1998) Oldest known sea turtle. Nature 392: 705-708

IUCN (International Union for the Conservation of Nature) (2004) Red List of threatened species. IUCN, Gland and Cambridge. Also available at: www.redlist.org

Jacobs GH (1993) The distribution and nature of colour vision among the mammals. Biol Rev Camb Phil Soc 68: 413-471

Jacobs GH, Neitz J, Krogh KJ (1996) Electroretinogram flicker photometry and its applications J Opt Soc Am A 13: 641-648

> Lamb TD (1995) Photoreceptor spectral sensitivities: common shape in the long-wavelength region. Vision Res 35: 3083-3091

> Lee BB, Martin PR, Valberg A (1989) Sensitivity of macaque retinal ganglion cells to chromatic and luminance flicker. J Physiol 414:223-243

> Levenson DH, Eckert SA, Crognale MA, Deegan JF, Jacobs GH (2004) Photopic spectral sensitivity of green and loggerhead sea turtles. Copeia 2004(4):908-914

> Lewison RL, Crowder LB (2007) Putting longline bycatch of sea turtles into perspective. Conserv Biol 21:79-86

> Lewison RL, Crowder LB, Freeman S (2004) Quantifying the effects of fisheries on threatened species: the impact of pelagic longlines on loggerhead and leatherback sea turtles. Ecol Lett 7:221-231

Liebman PA, Granda AM (1971) Microspectrophotometric measurements of visual pigments in two species of turtle, Pseudemys scripta and Chelonia mydas. Vision Res 11: 105-114

Morgan PJ (1990) The leatherback turtle: sea turtles and their conservation. National Museum of Wales, Cardiff

Rhodin A, Ogden JA, Conlogue GJ (1981) Chondro-osseous morphology of Dermochelys coriacea, a marine reptile with mammalian skeletal features. Nature 290:244-246

Southwood A, Fritsches K, Brill R, Swimmer Y (2008) Sound, chemical, and light detection in sea turtles and pelagic fishes: sensory-based approaches to bycatch reduction in longline fisheries. Endang Species Res 5:225-238

Spotila JR, Reina RD, Steyermark AC, Plotkin PT, Paladino F (2000) Pacific leatherback turtles face extinction. Nature 405:529-530

Tsukahara Y, Blair NP, Spellman Eappen DC, May JJ, Takahashi A, Shah GK, Viana MAG (1992) Ketamine suppresses ischemic injury in the rabbit retina. Invest Ophthalmol Vis Sci 33:1822-1825

Watson AB (1986) Temporal sensitivity. In: Boff KR, Kaufman L, Thomas JP (eds) Handbook of perception and human performance I. Wiley, New York

Witzell WN (1999) Distribution and relative abundance of sea turtles caught incidentally by the U.S. pelagic longline fleet in the western North Atlantic Ocean, 1992-1995. Fish Bull (Wash DC) 97:200-211

Submitted: September 16, 2007; Accepted: June 1, 2008

Proofs received from author(s): August 19, 2008 